gun design practice by using a cylinder which was subjected to progressive internal and external loading, and this enabled him consistently to reach pressures of 50 kilobars. Using a two-stage apparatus of this design he achieved pressures of up to 100 kilobars, but with the consequent penalty of a very big reduction in working volume. Bridgman probably achieved pressures of 200 kilobars in a very restricted volume in his anvil design by using what he termed "the principle of massive support". The reproducible and indeed commercial production of artificial diamonds in 1955 by a research team in the General Electric Co. of America was achioved using a 'belt' apparatus which was a development of the anvil principle. Since then there have been considerable developments and there are now several proved designs using the principle of massive support which can be used to subject samples of materials of worth-while size to pressures in excess of 100 kilobars at temperatures up to and above $2,000^{\circ} \mathrm{C}$.

This book is edited by one of the original General Electric Co. team, and the authors of the various chapters have all made major contributions to this field of research. The book really forms a progress report on the present state of the art of carrying out various fundamental experiments under pressures in excess of 20 kilobars at temperatures from a few degrees above absolute zero to more than $2,000^{\circ} \mathrm{C}$. Chapters are devoted to the general principles of highpressure apparatus design, high-pressure optical and electrical measurements, Debye-Scherrer X-ray techniques for high-pressure studies, high-temperature methods at high pressure, high pressure at low temperature, etc.

The editor and contributors to this book are to be congratulated on having written a most valuable addition to the three or four books available on highpressure techniques. The publishers are also to be complimented on their high standards in the production of this volume.

B. Crossland

\section{METHODS IN ELECTROPHYSIOLOGY}

Electrophysiological Methods in Biological Research By Dr. Jan Bureš, Dr. Mojmir Petráñ and Dr. Jozef Zachar. Pp. 515. (Prague: Publishing House of the Czechoslovak Academy of Sciences, 1960.) Cena vázaného vytisku Kěs 54.

THIS is an excellent book which will be of real use to neurophysiologists. It not only describes methods and equipment in general, but also sets out in detail how to perform a large number of particular experiments, from measuring the membrane potential of Nitella to making stereotaxic lesions in the brain of the cat. I myself know of no other book that does the same. The English translation is impeccable.

Chapter 1 is a first-class account of electrochemistry and membrane theory, with a better outline of the sodium theory of the nerve impulse than is to be found in most Western physiology textbooks. Chapter 2 deals with apparatus and technique. The electronies is sound but somewhat dated, without transistors; but the later sections on locating faults, getting rid of alternating-current hum, etc., and on how to make electrodes are highly practical. Chapters 3-9 introduce, and then describe, experi- ments on membrane potentials, the nerve impulse, muscle, the electroretinogram, the spinal cord, the cerebral cortex and subcortical structures-to mention the main headings. An appendix contains stereotaxic atlases of the brain of the cat, rabbit and rat.

The description of each experiment is divided into: problem, principle, apparatus, other requirements, object (animal preparation used), procedure, results and conclusions. The instructions are lucid and full; for example, detailed drawings are given of the dissection of nerves in the frog's leg. References are given throughout (the majority to papers in English), but in many instances the records illustrated do not appear to be those of the original papers; from which we may conclude that the authors have performed many of the experiments themselves. From this no doubt stems the high quality and freshness of their presentation.

P. A. Merton

\section{LIPIDS AND LIFE}

\section{Lipide Metabolism}

Edited by Prof. Konrad Bloch. Pp. xiii +411 . (New York and London: John Wiley and Sons, Inc.. 1960.) 84s.

T IPIDS are biochemical entities of sometimes 1 vague affiliations but most are derivatives of higher fatty acids. Until recently they were an unpopular and generally neglected subject for research, but the past decade or two has brought a striking change, reflected in the present-day wealth of research publications on lipid chemistry, metabolism and functions. The importance of lipids in the functioning of living tissue is no longer minimized.

Assessment of this advancing tide of knowledge is a matter for the specialist. The book in question contains eight monographs, all the work of acknowledged authorities and outstanding research workers in the fields they survey. The editor is likewise prominent among lipid chemists. As he comments in his preface, some important subjects had to be omitted to ensure prompt publication. One such is the biosynthesis of cholesterol, a field with which Prof. Bloch's name is closely associated. Perhaps he felt it unnecessary to include this topic, since a contemporary review on it was being prepared for publication elsewhere ${ }^{1}$, but there is no reference in the present book to a source of information on cholesterol synthesis, for example, in sections where other aspects of cholesterol metabolism are discussed.

The subjects discussed are: (1) synthesis and oxidation of saturated fatty acids, by D. E. Green and S. J. Wakil, (2) metabolism of unsaturated fatty acids, by J. F. Mead, (3) metabolism and function of phosphatides, by R. J. Rossiter and K. P. Strickland, (4) metabolism of glycerides, by B. Borgström, (5) lipolytic enzymes, by M. Kates, (6) hormonal regulation of fatty acid metabolism, by R. G. Langdon, (7) formation and metabolism of bile acids, by $\mathrm{S}$. Bergström, H. Danielsson and B. Samuelsson, (8) chemistry and metabolism of bacterial lipids, by F. Asselineau and E. Lederer. Some of these topics are more extensive than others, necessitating a more condensed appraisal, but all authors have succeeded in giving readable accounts of the present state of knowledge and of the steps by which it was reached. Sometimes elimination of all but a main theme gives greater cohesion; for example, Chapter 1 concentrates 